Volume 11, Nomor 2, November 2019, pp 248-261 Copyright (C) 2017 Jurnal Akuntansi Maranatha, Program Studi Akuntansi, Fakultas Ekonomi, Universitas Kristen Maranatha. ISSN 2085-8698 | e-ISSN 2598-4977. http://journal.maranatha.edu

\title{
Analisa Persepsi Konsumen Atas Kualitas Pelayanan Elektronik Terhadap Niat Komplain Konsumen Massively Multiplayer Online Role-Playing Games
}

\author{
Handy Andriyas \\ Fakultas Ekonomi Program Studi Magister Manajemen Universitas Katolik Parahyangan \\ (Jl. Merdeka No.30, Bandung) \\ andriyashandy@gmail.com \\ Gerardus Herlangga Himawan \\ Fakultas Ekonomi Program Studi Manajemen Universitas Katolik Parahyangan \\ (Jl. Ciumbuleuit No.94, Bandung) \\ gerardusherlangga@gmail.com
}

\begin{abstract}
This study aims to determine the influence of consumer perceptions of the quality of Gravindo's electronic services to the intentions of Ragnarok Online Gravindo's consumer complaints. Methods of data analysis using multiple regression analysis. The sampling technique used in this study was nonprobability sampling, with the type of purposive sampling type judgment sampling, therefore the researchers choose respondents who had played Gravindo Ragnarok Online with the reason that the respondents knew and felt the services Gravindo provided in Gravindo's Ragnarok Online game. The number of respondents is 100 people. The results of multiple regression analysis show that from the four dimensions of electronic service quality variables (reliability, customer service, security, and web design) conducted by Gravindo, there are only three dimensions that significantly influence consumer complaint intentions, namely reliability, customer service, and security. This result also shows that Gravindo still needs to improve the quality of electronic services to be able to reduce consumer complaint intentions and be able to increase customer satisfaction going forward. Based on the results of the study, the quality of electronic services carried out by Gravindo had an effect of $78.4 \%$ on consumer complaint intentions.
\end{abstract}

Keywords: Electronic Service Quality, Consumer Complaint Intentions 


\section{Pendahuluan}

Berbagai aplikasi berbasis internet sudah menyatu dengan masyarakat modern sekarang ini, dan tentunya hal ini menciptakan banyak peluang bisnis dan memperkaya aktivitas sehari-hari konsumen, salah satu aktivitas online yang paling umum adalah gaming (Lan \& Ying, 2011). Online games terus memimpin pertumbuhan pada tahun 2015 dari pertumbuhan keseluruhan dari semua pasar game (EIBN, 2016).

Salah satu jenis online game yang populer adalah Massively Multiplayer Online Role-playing Games (MMORPGs). MMORPG adalah lingkungan berbasis shared web di mana banyak pengguna secara bersamaan berpartisipasi dalam berbagai skenario permainan dengan peran yang berbeda (Griffiths, Davies, \& Chappell, 2004; Moon, Hossain, Sanders, Garrity, \& Jo, 2013). MMORPGs telah menjadi jenis yang paling populer dari online game (Achterbosch \& Pierce, 2015). MMORPGs merupakan salah satu jenis online game yang menonjol karena kekayaan dalam plot dan elemen permainan, MMORPGs menarik sebagian besar pengguna stabil yang bersedia membayar uang untuk aset virtual di permainan tersebut (CNNIC, 2015).

Salah satu MMORPGs yang paling terkenal di Indonesia adalah Ragnarok Online. Ragnarok Online dibuat berdasarkan cerita dan latar belakang yang sama dari komik terkenal berjudul "Ragnarok" yang ditulis oleh Lee MyoungJin, komik ini kemudian dikembangkan menjadi sebuah online game yang memfokuskan fitur komunitas antar pemainnya. Ragnarok Online didesain dengan pilihan variasi job / role yang banyak dan juga menarik, garis cerita dan tempat-tempat Ragnarok Online juga diambil dari cerita Ragnarok asli untuk menambah kepuasan para pemain (ragnarok Lyto game, 2017).
Perusahaan online game publisher Gravindo telah resmi memegang lisensi Ragnarok Online Indonesia dan melakukan peluncuran ulang Ragnarok Online Indonesia yang baru dengan nama Ragnarok Online Gravindo, kini Gravindo bertanggungjawab sepenuhnya dalam mengelola permainan Ragnarok Online Gravindo.

Namun pada awal pembukaan Ragnarok Online Gravindo tanggal 8 Februari 2017 (Ragnarok Online Gravindo, 2017) hingga sekarang, peneliti mengamati berbagai respon negatif dari para pemain Ragnarok Online Gravindo. Di dalam permainan, muncul banyak keluhan dan kekecewaan yang dikomunikasikan antar pemain Ragnarok Online Gravindo. Komplain konsumen dianggap penting bagi perusahaan untuk mengetahui reaksi pelanggan atas suatu pelayanan perusahaan, terutama pada perusahaan jasa (Kim, Kim, Im, \& Shin, 2003; Kim, M., \& Mattila, 2010). Bedasarkan fenomena di atas, maka dilakukanlah preliminary research dengan melakukan wawancara kepada 19 pemain yang merasa tidak puas atas permainan Ragnarok Online Gravindo. Dari hasil wawancara tersebut didapati hasil bahwa 19 dari 19 responden menunjukkan niat komplain yang tinggi terhadap permainan Ragnarok Online Gravindo, bahkan 17 responden tersebut pernah melakukan aktivitas-aktivitas komplain pada Gravindo.

Mereka mengeluhkan koneksi server permainan yang tidak lancar dan tidak stabil. Hal ini sering terjadi terutama pada siang dan sore hari dimana terjadi lonjakan pada banyaknya jumlah pemain yang masuk dalam permainan tersebut, sehingga hal ini tentunya sangat mengganggu kenyamanan bermain. Selain itu mereka mengeluhkan kapasitas server yang tidak sebanding dengan jumlah pemain yang masuk, sehingga banyak pemain yang tidak bisa memasuki permainan. Terjadi banyak kesalahan atau berhenti berfungsinya sistem operasi permainan (crash) pada Ragnarok Online 
Gravindo yang sangat lama ditangani oleh pihak Gravindo, seperti pintu gerbang pada permainan (warp portal) yang tidak bisa dimasuki oleh para pemain dan npc (karakter yang dimainkan oleh komputer dan tidak bisa dikontrol oleh pemain) yang tidak bisa berfungsi sebagai mana mestinya. Beberapa responden mengaku mendapatkan cash item yang tidak sesuai dengan yang dijanjikan pada situs web Gravindo. Beberapa responden juga mengaku mengalami permasalahan pada saat pengisian virtual cash, ketika telah melakukan transaksi pengisian virtual cash, ternyata saldo responden tersebut tidak terisi. Sebagian besar dari responden merasa resah karena banyak munculnya bot player (karakter pemain yang dijalankan otomatis oleh program komputer) dan penanganan yang belum serius pada bot player tersebut oleh Gravindo, hal ini berbahaya karena menggunakan program bot merupakan aktivitas ilegal dan membuat pemain lain merasa dicurangi dalam permainan. Pihak game master (orang yang berperan sebagai pengurus, pengatur, dan moderator dalam suatu permainan) dari Ragnarok Online Gravindo dirasa jarang keberadaanya oleh pemain dan seringkali kurang bersedia dalam menyelesaikan permasalahan pemain sehingga pemain merasa kurang dipedulikan. Pihak game master juga dirasa jarang turun ke lapangan untuk melakukan pengecekan secara langsung pada permasalahan teknis permainan dan permasalahan pemain. Sebagian dari responden juga merasa pihak dari Gravindo tidak terlalu memperhatikan keluhan-keluhan yang diajukan oleh para pemain.

Berdasarkan pandanganpandangan yang telah didapat dari preliminary research yang telah disebutkan sebelumnya, penulis melihat bahwa masalah utama terletak pada buruknya kualitas pelayanan elektronik Gravindo pada permainan Ragnarok Online Gravindo yang menjadi penyebab utama tingginya niat komplain konsumen. Banyak pemain yang kecewa karena pelayanan Gravindo yang belum memuaskan, bahkan seringkali pemain dibuat kesal dan marah. Pelanggan yang tidak puas, bisa melakukan perilaku tidak langsung kepada perusahaan, seperti memutuskan keluar sebagai pelanggan atau melakukan komunikasi negatif dari mulut ke mulut dari pada menyatakan komplain secara langsung kepada perusahaan (Best \& Andreasen, 1976; Bach \& Kim, 2012) dan hal ini tentunya sangat berbahaya bagi perusahaan.

Dengan memperhatikan masalah ini, maka penulis tertarik untuk melakukan penelitian mengenai persepsi konsumen atas kualitas pelayanan elektronik Gravindo dan bagaimana pengaruhnya terhadap niat komplain konsumen Ragnarok Online Gravindo. Untuk itu, penulis ingin melakukan penelitian yang berjudul "Pengaruh Persepsi Konsumen atas Kualitas Pelayanan Elektronik Gravindo Terhadap Niat Komplain Konsumen Ragnarok Online Gravindo".

\section{Kerangka Teoritis dan Hipotesis}

\section{Kualitas Pelayanan Elektronik}

Banyak peneliti melakukan pengembangan teori kualitas pelayanan elektronik yang memang khusus digunakan untuk mengevaluasi suatu pelayanan yang diberikan lewat jaringan internet ((Liang, 2012; Tan, Benbasat, \& Cenfetelli, 2016; Hamari, Hanner, \& Koivisto, 2017; Liao, Cheng, \& Teng, 2019). Menurut Boyer dan kawan-kawan (2002), Salah satu metode yang diciptakan untuk mengevaluasi kualitas pelayanan elektronik adalah eTailQ (Wolfinbarger \& Gilly, 2003; Li \& Luo, 2015; Yarimoglu, 2015; Alanezi \& Sellami, 2019). Menurut Yarimoglu (2015), metode eTailQ dapat dibandingkan dengan metode SERVQUAL (Parasuraman, Zeithaml, \& Berry, 1985; Hamari, Hanner, \& Koivisto, 2017). Perbedaan utama diantara kedua metode tersebut adalah persepsi konsumen atas karyawan merupakan peran utama 
dalam SERVQUAL, namun dalam penyampaian jasa elektronik, konsumen berinteraksi dengan perusahaan melalui technical interface, bukan melalui karyawan (Wolfinbarger \& Gilly, 2003)

Wolfinberger dan Gilly (2003), dalam penelitiannya yang berjudul "eTailQ: dimensionalizing, measuring and predicting etail quality" mengungkapkan bahwa kualitas pelayanan elektronik memiliki 4 dimensi utama yaitu, Reliability, Website Design, Security, dan Customer Service. Selanjutnya Wolfinberger dan Gilly (2003) mengidentifikasikan indikator-indikator sebagai alat untuk mengukur kualitas pelayanan elektronik, yaitu:

- Reliability, yaitu kemampuan perusahaan dalam memberikan pelayanan yang tepat dan memuaskan

- Website Design, yaitu mencakup semua elemen dari pengalaman konsumen di website perusahaan, termasuk navigasi, pencarian informasi, proses permintaan, dan personalisasi yang tepat

- Security, yaitu keamanan dalam melakukan pembayaran dan privasi pada informasi konsumen

- Customer Service, yaitu layanan yang digunakan untuk menyelesaikan masalah dengan responsif dan kesediaan perusahaan untuk membantu permasalahan pelanggan.

\section{Niat Komplain Konsumen}

Perilaku komplain merupakan salah satu tanggapan ketidakpuasan yang dirasakan di fase paska pembelian (Singh, 1988). Perilaku komplain konsumen merupakan seperangkat respon ketidakpuasan konsumen, hal ini adalah sebuah ekspresi eksplisit dari ketidakpuasan, tetapi ketidakpuasan hanya salah satu pemicu dari perilaku tersebut, ketidakpuasan yang terjadi berpengaruh pada niat komplain konsumen (Singh, 1988; Gounaris, Dimitriadis, \& Stathakopoulos, 2010). Perilaku komplain konsumen dipicu oleh ketidakpuasan yang diterima (Crie, 2003;
Sharma, Marshall, Alan Reday, \& $\mathrm{Na}$ 2010; Hansen, Wilke, \& Zaichkowsky, 2010). Tanpa persepsi negatif, respon konsumen tidak bisa memenuhi syarat sebagai perilaku komplain konsumen (Boote, 1998; Bach \& Kim, 2012; Nimako \& Mensah, 2012; Şengül, ÇAVUŞ, \& TAŞKIN, 2018).

Perilaku konsumen dapat diprediksi melalui niat atau intensnya (Ajzen \& Fishbein, 1977). Ajzen dan Fisbein (1977) mengatakan, cara yang paling efektif untuk mengetahui apakah individu akan menampilkan atau tidak menampilkan suatu perilaku adalah dengan menanyakan atau mengetahui niat individu tersebut untuk melakukan suatu perilaku. Niat komplain merupakan motivasi yang didorong oleh kegagalan perusahaan untuk menawarkan produk atau jasa yang memenuhi kebutuhan pelanggan, dan pelanggan akan cenderung membuat rencana atau mengambil tindakan untuk mengungkapkan ketidakpuasanya (Jacoby \& Jaccard, 1981; Gyung Kim, Wang, \& Mattila, 2010).

Jagdip Singh (1988), dalam penelitiannya yang berjudul "Consumer Complaint Intentions and Behavior: Definitional and Taxonomical Issues" mengungkapkan bahwa niat komplain memiliki 3 dimensi utama yaitu, Voice, Private dan Third Party. Selanjutnya Jagdip Singh (1988) mengidentifikasikan indikator-indikator sebagai alat untuk mengukur niat komplain konsumen, yaitu:

- Voice, yaitu tingkat keinginan konsumen untuk mencari ganti rugi dari perusahaan

- Private, yaitu tingkat keinginan konsumen untuk melakukan komunikasi negatif dari mulut ke mulut

- Third Party, yaitu tingkat keinginan konsumen untuk meminta bantuan pada pihak ketiga seperti lembaga konsumen atau lembaga hukum dalam menyelesaikan permasalahan. 


\section{Model Penelitian Dan Pengembangan Hipotesis}

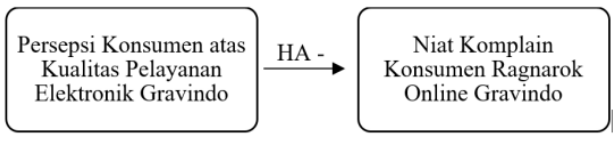

\section{Gambar 1 \\ Model Penelitian}

HA - :Semakin baik persepsi konsumen atas kualitas pelayanan elektronik Gravindo, maka niat komplain konsumen Ragnarok Online Gravindo akan semakin rendah.

\section{Metode Penelitian}

\section{Jenis Penelitian}

Menurut Sekaran dan Bougie (2013) metode penelitian adalah strategi umum yang dianut dalam pengumpulan analisis data yang diperlukan untuk menjawab persoalan yang dihadapi. Metode penelitian yang digunakan adalah metode deskriptif untuk memperoleh gambaran mengenai situasi yang terjadi dengan cara pengumpulan data, pengolahan data, dan analisa secara kuantitatif yang akhirnya menarik kesimpulan berdasarkan hasil pengelolaan data. Berdasarkan tujuan yang ingin dicapai, penelitian ini merupakan applied research (penelitian terapan), karena penelitian ini diarahkan untuk mendapatkan informasi yang dapat digunakan untuk memecahkan sebuah masalah.

Penelitian ini menggunakan rancangan survey, yaitu penelitian yang mengambil sampel dari suatu populasi dan menggunakan kuesioner sebagai alat pengumpulan data (Sugiyono, 2012). Penelitian survey ini digunakan dengan maksud untuk menjelaskan hubungan antara variabel-variabel melalui pengujian sebuah hipotesis sehingga disebut juga sebagai explanatory research.

\section{Populasi dan Sampel}

Populasi menurut Uma Sekaran (2013) mengacu pada keseluruhan pada suatu kelompok orang, peristiwa, atau sesuatu yang menjadi perhatian penulis untuk diteliti dan pada akhirnya akan ditarik sebuah kesimpulan (berdasarkan sampel statistik). Populasi dalam penelitian ini adalah pemain Ragnarok Online Gravindo di seluruh Indonesia.

Teknik pengambilan sampel yang digunakan peneliti dalam penelitian ini adalah nonprobability sampling, dengan jenis purposive sampling tipe judgment sampling. Dalam teknik sampling ini, yang dianggap sebagai anggota sampel adalah individu atau subjek yang berada di tempat yang paling menguntungkan atau dalam posisi terbaik untuk memberikan informasi yang diperlukan, maka dari itu peneliti memilih responden yang telah bermain Ragnarok Online Gravindo, dengan alasan agar responden telah mengetahui dan merasakan pelayanan yang diberikan Gravindo dalam permainan Ragnarok Online Gravindo, dan oleh sebab itu responden mampu menjawab kuesioner yang diajukan. Menurut Aaker (2008), untuk dapat menghitung sampel minimum yang dapat mewakili populasi, rumus yang dapat digunakan sebagai berikut:

$$
\mathrm{n}=\frac{0.25 \times Z^{2}}{\alpha^{2}}
$$

$$
\begin{aligned}
& \mathrm{n}=\text { Ukuran sampel minimum } \\
& \mathrm{z}=\text { Nilai } \mathrm{Z} \text { untuk interval } \\
& \text { kepercayaan } \alpha \\
& \mathrm{e}=\text { Sampling error }
\end{aligned}
$$

Penulis mengambil asumsi $\alpha=10 \%$ dan interval kepercayaan sebesar $95 \%$ maka pada tabel $\mathrm{Z}$ diperoleh nilai $\mathrm{Z}=1,96$. Berdasarkan asumsi tersebut dapat dihitung sampel minimum sebesar:

$$
\begin{aligned}
& \mathrm{n}=\frac{0.25 \times Z^{2}}{\alpha^{2}} \\
& \mathrm{n}=\frac{0.25 \times(1,96)^{2}}{(0.05)^{2}}
\end{aligned}
$$


$\mathrm{n}=96,4$

$\mathrm{n}=97$ responden

Maka ukuran sampel minimum yang diperoleh dan mewakili populasi adalah 97 responden, namun untuk menghindari kesalahan dan meningkatkan tingkat akuritas peneliti memutuskan untuk menggunakan 100 responden.

\section{Teknik Pengumpulan Data}

Dalam penelitian ini, penulis mengumpulkan data yang dibutuhkan dengan menggunakan teknik sebagai berikut:

\section{Literature survey}

penulis melakukan studi kepustakaan yang dilakukan dengan cara mempelajari artikel, jurnal dan bukubuku yang berkaitan dengan penelitian yang sedang penulis lakukan.

2. Field research

- Wawancara terhadap para pemain Ragnarok Online Gravindo. Wawancara ini dilakukan untuk mengetahui akar permasalahan sebagai penyebab niat komplain yang tinggi terhadap Ragnarok Online Gravindo.

- Menyebarkan kuesioner tertutup yang berisi pertanyaan mengenai seputar persepsi atas kualitas pelayanan Ragnarok Online Gravindo dan niat komplain pelanggan Ragnarok Online Gravindo, kuesioner akan dibagikan melalui internet.

- Melakukan pengamatan secara langsung pada objek yang diteliti.

\section{Definisi Operasionalisasi Variabel dan Pengukurannya}

1. Variabel Bebas, Kualitas Pelayanan Elektronik (X).

Menurut Wolfinberger dan Gilly (2003) kualitas pelayanan elektronik memiliki 4 dimensi utama yaitu, Reliability, Website Design, Security/Privacy, dan Customer Service.

a. Reliability

Indikator dari reliability ini antara lain: koneksi server yang lancar pada saat bermain Ragnarok Online Gravindo, koneksi server yang stabil pada saat bermain Ragnarok Online Gravindo, Gravindo dapat diandalkan dalam menangani masalah pelanggaran yang terjadi pada Ragnarok Online Gravindo (bot player, cheat, dan pelanggaran lainnya), dan konsumen mendapatkan item cash yang sesuai dengan yang dijanjikan pada web Ragnarok Online Gravindo. Skala yang digunakan adalah skala interval.

b. Customer Service (X2)

Indikator dari Customer Service ini antara lain: Gravindo pasti menginformasikan kapan tepatnya maintenance akan dilakukan, Gravindo melakukan maintenance dengan waktu yang cepat, Game Master Ragnarok Online Gravindo turun langsung ke lapangan untuk membantu pemain yang bermasalah, Game Master Ragnarok Online Gravindo selalu bersedia dalam membantu pemain yang bermasalah, Gravindo bergerak cepat dalam menangani masalah teknis yang terjadi pada Ragnarok Online Gravindo ( gagal patch, gagal login, dan error), mudah untuk mengirimkan keluhan pada Ragnarok Online Gravindo, pihak Gravindo memberikan solusi pada keluhan- 
keluhan yang dikirimkan oleh pemain. Skala yang digunakan adalah skala interval.

c. Security / Privacy (X3)

Indikator dari security / privacy ini antara lain: konsumen merasa aman pada saat mengisi saldo cash Ragnarok Online Gravindo, konsumen merasa aman pada saat melakukan transaksi cash item Ragnarok Online Gravindo, konsumen merasa Gravindo melindungi para pemain dari kejahatan berbentuk hacking, konsumen merasa Gravindo melindungi dan menjamin keamanan data para pemain. Skala yang digunakan adalah skala interval.

d. Web Design (X4)

Indikator dari Web Design ini antara lain: Web Ragnarok Online Gravindo menyediakan informasi penting bagi para pemain, informasi yang terdapat pada web Ragnarok Online Gravindo mudah dipahami, informasi yang terdapat pada web Ragnarok Online Gravindo disajikan dengan menarik, desain tampilan pada web Ragnarok Online Gravindo menarik. Skala yang digunakan adalah skala interval.

2. Variabel dependent, Niat Komplain (Y)

a. Voice (Y1)

Indikator dari voice ini antara lain : keinginan untuk melupakan insiden tersebut dan tidak melakukan apapun, keinginan untuk melakukan komplain jika terjadi permasalahan selanjutnya, dan keinginan untuk langsung melakukan komplain pada saat permasalahan terjadi. Skala yang digunakan adalah skala interval.

b. Private (Y2)

Indikator dari private ini antara lain: keinginan untuk tidak akan bermain Ragnarok Online
Gravindo lagi, keinginan untuk menceritakan pengalaman buruk tersebut kepada teman dan kerabat, dan keinginan untuk merekomendasikan kepada teman dan kerabat untuk tidak bermain Ragnarok Online Gravindo. Skala yang digunakan adalah skala interval.

c. Third Party (Y3)

Indikator dari third party ini antara lain: keinginan untuk melapor kepada lembaga konsumen agar menyelesaikan masalah Ragnarok Online Gravindo, keinginan untuk menceritakan pada media tentang pengalaman buruk tersebut, dan keinginan untuk meminta lembaga konsumen untuk dapat memperingatkan konsumen yang lainnya. Skala yang digunakan adalah skala interval.

\section{Metode Analisa Data}

Analisis data adalah tahap yang paling penting dan menentukan dalam suatu penelitian. Data yang diperoleh selanjutnya dianalisa dengan tujuan menyederhanakan data ke dalam bentuk yang lebih mudah dibaca dan diinterpretasikan. Selain itu data dimanfaatkan agar dapat dipakai untuk menjawab rumusan masalah yang diajukan dalam penelitian.

\section{Deskriptif Kuantitatif}

Dalam penelitian ini, untuk menganalisis dan menginterpretasikan data secara kuantitatif digunakan alat bantu perhitungan statistik sehingga memudahkan penafsiran data mentah yang diperoleh. Alat ukur utama yang digunakan dalam penelitian ini adalah kuesioner. Lalu data akan diolah dan memperoleh data yang valid dan reliabel dengan menggunakan uji validitas dan uji reliabilitas.

a. Uji Validitas

Uji validitas yang digunakan dalam penelitian ini adalah Face Validity, yang merupakan dasar dan index 
minimum dari Content Validity. Menurut Uma Sekaran (2013), hal tersebut dilakukan dengan cara menunjukkan dan meminta persetujuan akan indikator-indikator pengukuran yang ada pada kuesioner yang diperoleh dari teori-teori seorang ahli, dalam penelitian ini adalah persetujuan dari dosen pembimbing. Selain itu peneliti melakukan pengujian validitas menggunakan alat pengujian validitas pearson, suatu alat ukur dikatakan valid apabila $\mathrm{r}$ hitung $\geq$ $r$ tabel. Nilai $r$ tabel yang diperoleh dari tabel $r$ adalah sebesar 0,3610 dengan sampel sebanyak 30 responden, sehingga didapat df (30-2) $=28$ dan $\alpha$ sebesar 0,05 .

b. Uji Reliabilitas

Uji reliabilitas yang digunakan adalah metode interitem consistency, yaitu adalah tes konsistensi pada jawaban responden untuk semua pertanyaan dalam suatu alat pengukuran. Menurut Uma Sekaran (2013), hal tersebut untuk menunjukkan bahwa jika pertanyaan-pertanyaan pada suatu alat pengukuran berasal dari konsep yang sama, maka tingkat korelasi pertanyaan satu dengan yang lainnya akan kuat. Karena jawaban kuesioner merupakan pilihan berganda, maka penulis memutuskan untuk menggunakan Cronbach's Coefficient Alpha. Menurut Sekaran dan Bougie (2013), dasar pengambilan keputusan untuk uji reliabilitas agar sebuah item dapat dinyatakan reliabel adalah sebagai berikut:

- Jika koefisien cronbach alpha $\geq 0,80$ maka kuesioner memiliki reliabilitas baik.

- Jika koefisien cronbach alpha berada di sekitar 0,70 maka kuesioner memiliki reliabilitas yang cukup baik dan dapat diterima.

- Jika koefisien cronbach alpha $\leq 0,60$ maka kuesioner memiliki reliabilitas yang tidak baik.

\section{Hasil Penelitian dan Pembahasan}

\section{Uji Kualitas Data \\ Uji Validitas}

Tabel 1

Hasil Uji Validitas

\begin{tabular}{|c|c|c|c|c|}
\hline \multicolumn{2}{|c|}{ Variabel } & \multirow{2}{*}{$\begin{array}{c}\begin{array}{c}\text { R Hitung } \\
\text { (Pearson) }\end{array} \\
0.922\end{array}$} & \multirow{2}{*}{$\begin{array}{c}\text { R Tabel } \\
0.3610\end{array}$} & \multirow{2}{*}{$\begin{array}{c}\text { Kesimpulan } \\
\text { VALID }\end{array}$} \\
\hline \multirow{4}{*}{$\mathrm{X} 1$} & 1 & & & \\
\hline & 2 & 0.963 & 0.3610 & VALID \\
\hline & 3 & 0.822 & 0.3610 & VALID \\
\hline & 4 & 0.614 & 0.3610 & VALID \\
\hline \multirow{7}{*}{$\mathrm{X} 2$} & 5 & 0.604 & 0.3610 & VALID \\
\hline & 6 & 0.870 & 0.3610 & VALID \\
\hline & 7 & 0.847 & 0.3610 & VALID \\
\hline & 8 & 0.897 & 0.3610 & VALID \\
\hline & 9 & 0.909 & 0.3610 & VALID \\
\hline & 10 & 0.908 & 0.3610 & VALID \\
\hline & 11 & 0.944 & 0.3610 & VALID \\
\hline \multirow{4}{*}{$\mathrm{X} 3$} & 12 & 0.849 & 0.3610 & VALID \\
\hline & 13 & 0.925 & 0.3610 & VALID \\
\hline & 14 & 0.883 & 0.3610 & VALID \\
\hline & 15 & 0.918 & 0.3610 & VALID \\
\hline \multirow{4}{*}{$\mathrm{X} 4$} & 16 & 0.945 & 0.3610 & VALID \\
\hline & 17 & 0.850 & 0.3610 & VALID \\
\hline & 18 & 0.896 & 0.3610 & VALID \\
\hline & 19 & 0.932 & 0.3610 & VALID \\
\hline $\mathrm{Y} 1$ & 20 & 0.782 & 0.3610 & VALID \\
\hline
\end{tabular}




\begin{tabular}{|c|c|c|c|c|}
\hline & 21 & 0.760 & 0.3610 & VALID \\
\cline { 2 - 5 } & 22 & 0.779 & 0.3610 & VALID \\
\hline \multirow{3}{*}{ Y2 } & 23 & 0.858 & 0.3610 & VALID \\
\cline { 2 - 5 } & 24 & 0.801 & 0.3610 & VALID \\
\cline { 2 - 6 } & 25 & 0.709 & 0.3610 & VALID \\
\hline \multirow{3}{*}{ Y3 } & 26 & 0.771 & 0.3610 & VALID \\
\cline { 2 - 6 } & 27 & 0.721 & 0.3610 & VALID \\
\cline { 2 - 6 } & 28 & 0.734 & 0.3610 & VALID \\
\hline
\end{tabular}

Setelah melakukan pengujian melakukan IBM SPSS V18, semua item indikator yang ada pada tabel 3 di atas menunjukkan bahwa R-hitung diatas 0,3 maka semua item dapat dikatakan valid.

\section{Uji Reliabilitas}

\section{Tabel 2}

Hasil Uji Reliabilitas

\begin{tabular}{|c|c|c|c|}
\hline Dimensi & $\begin{array}{c}\text { Cronbach } \\
\text { Alpha }\end{array}$ & $\begin{array}{c}\text { Titik } \\
\text { Krisis }\end{array}$ & Kesimpulan \\
\hline $\mathrm{X} 1$ & 0.860 & 0.7 & Baik \\
\hline $\mathrm{X} 2$ & 0.939 & 0.7 & Baik \\
\hline $\mathrm{X} 3$ & 0.912 & 0.7 & Baik \\
\hline $\mathrm{X} 4$ & 0.926 & 0.7 & Baik \\
\hline $\mathrm{Y} 1$ & 0.656 & 0.7 & $\begin{array}{c}\text { Dapat } \\
\text { Diterima }\end{array}$ \\
\hline $\mathrm{Y} 2$ & 0.683 & 0.7 & $\begin{array}{c}\text { Dapat } \\
\text { Diterima }\end{array}$ \\
\hline $\mathrm{Y} 3$ & 0.622 & 0.7 & $\begin{array}{c}\text { Dapat } \\
\text { Diterima }\end{array}$ \\
\hline
\end{tabular}

Analisis Pengaruh Kualitas Pelayanan Elektronik Gravindo Terhadap Niat Komplain Konsumen Ragnarok Online Gravindo

Tabel 3

Koefisien Hasil Regresi

Coefficients $^{\mathrm{a}}$

\begin{tabular}{|c|c|c|c|c|c|c|}
\hline \multirow{2}{*}{\multicolumn{2}{|c|}{ Model }} & \multicolumn{2}{|c|}{ Unstandardized Coefficients } & \multirow{2}{*}{$\begin{array}{c}\begin{array}{c}\text { Standardized } \\
\text { Coefficients }\end{array} \\
\text { Beta }\end{array}$} & \multirow[b]{2}{*}{$t$} & \multirow[b]{2}{*}{ Sig. } \\
\hline & & $B$ & Std. Error & & & \\
\hline \multirow[t]{5}{*}{1} & (Constant) & 5,266 & .088 & & 59,645 & .000 \\
\hline & R_Mean & -281 &, 058 &,- 424 & $-4,820$ &, 000 \\
\hline & CS_Mean & - 163 &, 062 &,- 257 & $-2,602$ & .011 \\
\hline & S_Mean & -140 &, 063 & -232 & $-2,224$ &, 028 \\
\hline & WD_Mean & -,037 & .060 & -056 &,- 608 & .544 \\
\hline
\end{tabular}

Dependent Variable: $Y_{\text {_Mean }}$

Sumber: hasil pengolahan penulis

$\mathrm{Y}=5,266-0,424 \mathrm{X} 1-0,257 \mathrm{X} 2-0,232 \mathrm{X} 3+\mathrm{e}$

Hasil regresi tersebut diperoleh berdasarkan hasil nilai Beta yang terdapat pada tabel. Nilai sig. yang memiliki nilai $\geq 0.05$ tidak dimasukkan ke dalam model regresi berganda ini karena tidak berpengaruh secara signifikan. Oleh karena itu, dimensi website design tidak dimasukkan dalam model regresi berganda tersebut. Persamaan diatas dapat dijelaskan sebagai berikut:

1.

Dimensi Reliability (X1)
berpengaruh secara signifikan
sebesar 0,424 dan bernilai negatif,
yang artinya semakin tinggi kualitas
pelayanan elektronik khususnya
dalam hal reliability yang diberikan
oleh Gravindo dalam permainan
Ragnarok Online Gravindo, maka
akan semakin rendah pula niat
komplain konsumen Ragnarok
Online Gravindo. Melalui hasil
regresi tersebut, peneliti
menyimpulkan bahwa buruknya
kelancaran dan kestabilan koneksi
server pada permain Ragnarok
Online Gravindo, Gravindo yang
tidak bisa diandalkan dalam
menangani masalah pelanggaran
yang terjadi pada Ragnarok Online
Gravindo ( bot player, cheat, dan
pelanggaran lainnya), dan


ketidaksesuaian item cash yang didapatkan konsumen dengan yang dijanjikan pada web Ragnarok Online Gravindo akan meningkatkan niat komplain konsumen Ragnarok Online Gravindo. Buruknya kualitas pelayanan elektronik Gravindo dalam hal reliability merupakan hal yang berpengaruh paling besar pada terjadinya perilaku komplain konsumen Ragnarok Online Gravindo yang tinggi.

2. Dimensi Customer Service (X2) berpengaruh secara signifikan sebesar 0,257 dan bernilai negatif, yang artinya semakin tinggi kualitas pelayanan elektronik khususnya dalam hal customer service yang diberikan oleh Gravindo dalam permainan Ragnarok Online Gravindo, maka akan semakin rendah pula niat komplain konsumen Ragnarok Online Gravindo. Melalui hasil regresi tersebut, peneliti menyimpulkan bahwa durasi waktu maintenance Ragnarok Online Gravindo yang lama, game master Ragnarok Online Gravindo yang tidak selalu turun langsung ke lapangan untuk membantu pemain yang bermasalah, game master Ragnarok Online Gravindo yang kurang bersedia dalam membantu pemain yang bermasalah, Gravindo yang bergerak lambat dalam menangani masalah teknis yang terjadi, kesulitan untuk mengirimkan keluhan pada Ragnarok Online Gravindo, dan pihak Gravindo yang kurang memberikan solusi pada keluhan-keluhan yang dikirimkan oleh pemain akan meningkatkan niat komplain konsumen Ragnarok Online Gravindo. Buruknya kualitas pelayanan elektronik Gravindo dalam hal customer service merupakan hal yang berpengaruh secara signifikan pada terjadinya perilaku komplain konsumen Ragnarok Online Gravindo yang tinggi. Jika adanya perbaikan terusmenerus pada customer service tentunya dapat mengurangi niat komplain konsumen Ragnarok Online Gravindo.

3. Dimensi Security (X3) berpengaruh secara signifikan sebesar 0,232 dan bernilai negatif, yang artinya semakin tinggi kualitas pelayanan elektronik khususnya dalam hal security yang diberikan oleh Gravindo dalam permainan Ragnarok Online Gravindo, maka akan semakin rendah pula niat komplain konsumen Ragnarok Online Gravindo. Melalui hasil regresi tersebut, peneliti menyimpulkan bahwa perasaan tidak aman pada saat mengisi saldo cash Ragnarok Online Gravindo, perasaan tidak aman pada saat melakukan transaksi cash item Ragnarok Online Gravindo, Gravindo yang kurang melindungi para pemain dari kejahatan berbentuk hacking, dan Gravindo yang tidak melindungi dan menjamin keamanan data para pemain akan meningkatkan niat komplain konsumen Ragnarok Online Gravindo. Buruknya kualitas pelayanan elektronik Gravindo dalam hal security merupakan hal yang berpengaruh secara signifikan pada terjadinya perilaku komplain konsumen Ragnarok Online Gravindo yang tinggi. Keamanan data pemain adalah hal penting yang harus diperhatikan oleh pihak Gravindo, karena hal tersebut merupakan privasi konsumen yang harus dijaga untuk mencegah hal-hal yang tidak diinginkan.

4. Dimensi Website Design (X4) tidak berpengaruh secara signifikan terhadap niat komplain konsumen Ragnarok Online Gravindo, berdasarkan wawancara 
pendahuluan dan observasi yang dilakukan peneliti, konsumen Ragnarok Online Gravindo memang tidak terlalu mempermasalahkan website design Ragnarok Online Gravindo sebagai penyebab utama konsumen berniat melakukan perilaku komplain. Dalam observasi yang dilakukan, peneliti hanya menemukan permasalahan website design yang terletak pada tidak adanya history top up cash yang menjadi penting bagi konsumen sebagai bukti pengisian saldo cash dan bukti pembelian item cash.

\section{Simpulan dan Saran}

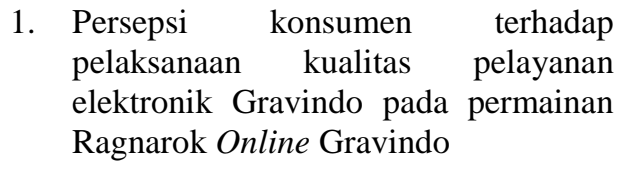

\section{Simpulan}

Pada analisa regresi berganda, setelah melalui uji $\mathrm{F}$ dan uji $\mathrm{T}$, diketahui bahwa dari empat dimensi yang terdapat di dalam variabel kualitas pelayanan elektronik Gravindo, terdapat tiga dimensi yang berpengaruh secara signifikan terhadap niat komplain konsumen Ragnarok Online Gravindo, ketiga dimensi tersebut adalah reliability, customer service, dan security. Dimensi yang pertama yaitu reliability berpengaruh negatif sebesar 0,424. Dimensi kedua yaitu customer service berpengaruh negatif sebesar 0,257 . Dimensi ketiga yaitu security berpengaruh negatif sebesar 0,232 . Hal tersebut menunjukkan bahwa reliability yang dilakukan oleh Gravindo berpengaruh paling besar pada terjadinya niat komplain konsumen Ragnarok Online Gravindo di dalam penelitian ini. Sedangkan dimensi website design tidak berpengaruh secara signifikan terhadap niat komplain konsumen Ragnarok Online Gravindo.

\section{Saran}

Berdasarkan hasil penelitian, peneliti mengungkapkan saran sebagai berikut:

1. Bedasarkan persepsi konsumen atas kualitas pelayanan elektronik Gravindo saat ini, perlu dilakukan perbaikan kualitas pelayanan elektronik agar dapat memuaskan konsumen dan mengurangi niat komplain konsumen Ragnarok Online Gravindo yang berbahaya pada saat ini. Berdasarkan regresi, terdapat tiga dimensi yang berpengaruh secara signifikan terhadap niat komplain konsumen Ragnarok Online Gravindo,

2. Selain Gravindo harus memperbaiki kualitas pelayanan elektronik yang menjadi penyebab utama tingginya niat komplain konsumen Ragnarok Online Gravindo, perbaikan penanganan komplain konsumen harus dilakukan, karena menurut hasil riset Technical Assistance Research Programs yang dilakukan oleh Naumann dan Giel (1995), 70-90\% pelanggan yang menyampaikan komplain akan melakukan bisnis lagi dengan perusahaan yang sama apabila ia puas dengan cara penanganan keluhannya. 


\section{Daftar Pustaka}

Aaker, D. A., Kumar, V., \& Day, G. S. (2008). Marketing research. John Wiley \& Sons.

Achterbosch, L., \& Pierce, R. (2015). Massively Multiplayer Online Role-Playing Games: The Past, Present, and Future. $A C M$ Computers in Entertainment, 9.

Ajzen, I., \& Fishbein, M. (1977). Attitudebehavior relations: A theoretical analysis and review of empirical research. Psychological bulletin, 888.

Alanezi, M. A., \& Sellami, A. (2019). An Unified Framework for Measuring E-Service Quality. Engineering, Technology \& Applied Science Research, 249-4254.

Bach, S. B., \& Kim, S. (2012). Online consumer complaint behaviors: The dynamics of service failures, consumers' word of mouth, and organization-consumer

relationships. International Journal of Strategic Communication, 59-76.

Best, A., \& Andreasen, A. R. (1976). Consumer responses to Unsatisfactory Purchases: a survey of perceiving defects, voicing complaints and obtaining redress. . Law and Society Review, 701.

Boote, J. (1998). Towards a comprehensive taxonomy and model of consumer complaining behaviour. Journal of Consumer Satisfaction, Dissatisfaction and Complaining Behavior, 140-151.

CNNIC. (2015). The census reports of the Internet development in China .

Crie, D. (2003). Consumers' complaint behaviour. Taxonomy, typology and determinants: Towards a unified ontology. . Journal of Database Marketing \& Customer Strategy Management, 60-79.
EIBN. (2016). EIBN Sector Reports Gaming Industry. EU- Indonesia Business Network.

Gounaris, S., Dimitriadis, S., \& Stathakopoulos, V. (2010). An examination of the effects of service quality and satisfaction on customers' behavioral intentions in e-shopping. Journal of services marketing, 142-156.

Griffiths, M., Davies, M., \& Chappell, D. (2004). Demographic Factors and Playing Variables in Online Computer Gaming. CyberPsychology \& Behaviour, 479-487.

Gyung Kim, M., Wang, C., \& Mattila, A. S. (2010). The relationship between consumer complaining behavior and service recovery: An integrative review. . International Journal of Contemporary Hospitality Management,, 975991.

Hamari, J., Hanner, N., \& Koivisto, J. (2017). Service quality explains why people use freemium services but not if they go premium: An empirical study in free-to-play games. . International Journal of Information Management, 14491459.

Hansen, T., Wilke, R., \& Zaichkowsky, J. (2010). Managing consumer complaints: differences and similarities among heterogeneous retailers. International Journal of Retail \& Distribution Management, 6-23.

Jacoby, J., \& Jaccard, J. J. (1981). The sources, meaning, and validity of consumer complaint behavior: A psychological analysis. Journal of retailing.

Kim, C., Kim, S., Im, S., \& Shin, C. (2003). The Effect of Attitude and Perception on Consumer Complaint Intentions. Journal of consumer marketing, 352-371. 
Kim, G., M., W. C., \& Mattila, A. S. (2010). he relationship between consumer complaining behavior and service recovery: An integrative review. nternational Journal of Contemporary Hospitality Management, 975-991.

Lan, Y.-H., \& Ying, J.-H. (2011). Predicting Online Game Loyalty Based on Need Gratification and Experiental Motives. Internet Research, 21(5), 581-598.

Li, H. A.-A., \& Luo, X. (2015). The interplay between value and service quality experience: eloyalty development process through the eTailQ scale and value perception. Electronic Commerce Research, 585-615.

Liang, Y.-H. (2012). Exploring The Relationship Between Perceived Electronic Service Quality, Satisfaction, and Personality: A Study of Taiwan's Online Game Industry. Total Quality Management \& Business Excellence, 949-963.

Liao, G. Y., Cheng, T. C., \& Teng, C. I. (2019). How do avatar attractiveness and customization impact online gamers' flow and loyalty? Internet Research, 349366.

Moon, J., Hossain, M., Sanders, G. L., Garrity, E. J., \& Jo, S. ( 2013). Player Commitment to Massively Multiplayer Online Role-Playing Games (MMORPGs): An Integrated Model. International Journal of Electronic Commerce, 7-38.

Nimako, S. G., \& Mensah, A. F. (2012). Motivation for customer complaining and non-complaining behaviour towards mobile telecommunication services. Asian Journal of Business Management, 310-320.
Parasuraman, A., Zeithaml, V. A., \& Berry, L. L. (1985). A conceptual model of service quality and its implications for future research. Journal of marketing, 41-50.

ragnarok Lyto game. (2017, January 23). ragnarok.lytogame. Retrieved from https://ragnarok.lytogame.com: https://ragnarok.lytogame.com/rog uide/intro/intro.asp

Ragnarok Online Gravindo. (2017, February 8), ragnarok.gravindo.id. Retrieved from https://ragnarok.gravindo.id: https://ragnarok.gravindo.id/news

Sekaran, U., \& Bougie, R. (2016). Research Methods for Business : A SkillBuilding Approach (Vol. 7). Chichester: Wiley.

Şengül, S., ÇAVUŞ, O., \& TAŞKIN, E. (2018). Analysis of E-Complaints for Restaurant Enterprises in the World's 50 Best Restaurant List. Journal of Tourism and Gastronomy Studies, 334.

Sharma, P., Marshall, R., Alan Reday, P., \& $\mathrm{Na}, \quad$ W. (2010). Complainers versus non-complainers: a multinational investigation of individual and situational influences on customer complaint behaviour. Journal of Marketing Management, 163-180.

Singh, J. (1988). Consumer complaint intentions and behavior: definitional and taxonomical issues. Journal of marketing, 93107.

Sugiyono. (2012). Metode Penelitian Kuantitatif Kualitatif dan $R \& D$. Bandung: Alfabeta.

Tan, C. W., Benbasat, I., \& Cenfetelli, R. T. (2016). An Exploratory Study of the Formation and Impact of Electronic Service Failures. Mis Quarterly, 1-29. 
Jurnal Akuntansi Maranathaø Volume 11 Nomor 2, November 2019 : 248-261

Wolfinbarger, M., \& Gilly, M. C. (2003). dimensionalizing, measuring and predicting etail quality. Journal of retailing, 183-198.

Yarimoglu, E. K. (2015). A Review of Service and E-Service Quality Measurements: Previous Literature and Extension. Journal of Economic \& Social Studies (JECOSS), 5(1). 